\title{
O colonialismo interno em O outro pé da sereia, de Mia Couto
}

\author{
Internal colonialism in Mia Couto's O outro pé da sereia
}

\author{
João Marques Lopes \\ Universidade de Lisboa / CLEPUL - Lisboa - Portugal
}

\begin{abstract}
Resumo: Neste artigo, sustentarei que, no romance $O$ outro pé da sereia (2006), Mia Couto está preocupado com os efeitos do "colonialismo interno" (Walter Mignolo). Nos começos do século XXI, no Moçambique pós-colonial, o empresário Casuarino e outras personagens do romance são agentes da "colonialidade do poder" transnacional e neo-liberal. Utilizam o "pós-colonialismo" e a "raça" para perpetuar hierarquias, desigualdades e injustiças à escala local, nacional e global. Pelo contrário, Mwadia, que é uma personagem de "fronteira", desafia simultaneamente o "colonialismo interno" e a "colonialidade do poder" independentemente das limitações raciais.
\end{abstract}

Palavras-chave: Mia Couto; Colonialismo interno; Colonialidade do poder; Pós-colonialismo

\begin{abstract}
In this article, I shall argue that Mia Couto's novel O outro pé da sereia (2006) deals with the effects of the so-called "internal colonialism" (Walter Mignolo). At the beginning of 21th century, in post-colonial Mozambique, businessman Casuarino and other characters of the novel are agents of the transnational and neo-liberal "coloniality of power". They utilize "post-colonialism" and "race" to perpetuate hierarchies, inequalities and injustices at local, national and global scales. On the contrary, Mwadia, which is a character that feels herself in a "in-between situation", challenges altogether the "internal colonialism" and the "coloniality of power" regardless of racial boundaries.
\end{abstract}

Keywords: Mia Couto; Internal colonialism; Coloniality of power; Post-colonialism

\section{Introdução}

No século XIX, o processo de independência e descolonização dos países latino-americanos teve como agentes fundamentais as pequenas elites brancas que descendiam dos colonos das metrópoles ibéricas. Não imbricaram seriamente as populações ameríndias ou os escravos oriundos de África, e não implicaram o regresso em massa dos colonizadores europeus. Apenas uma minoria de funcionários políticos, militares e administrativos retornou a casa no âmbito da transição do poder das metrópoles para as colónias.

Descontentes com a pressão tributária e com a dependência jurídico-politica decorrentes da sua sujeição a Espanha e a Portugal, os colonos reviam-se na Independência dos EUA, na Revolução Francesa e no liberalismo inglês. Portanto, quando se libertaram do jugo ibérico, as elites brancas não estavam propriamente em ruptura com o imaginário ocidental e euro- cêntrico. Pelo contrário, procuravam inscrever nos novos Estados-Nações que estavam a edificar os mecanismos institucionais, sociais e económicos postulados pela racionalidade iluminista, liberal e democrática dos séculos XVIII-XIX europeus.

Assim sendo, os saberes e os interesses das populações ameríndias foram silenciados em benefício das minorias brancas que detinham o poder e serviam como correia de transmissão mais ou menos conscientes dos projectos das principais potências metropolitanas de Novecentos, a Inglaterra e a Franca. Na construção de caminhos-de-ferro, de telégrafos, de troca de mercadorias, de importação de capitais e coisas quejandas, as novas nações independentes tinham agora como parceiros privilegiados os ingleses e os franceses. Não obstante a construção conjuntural de um imaginário que, por vezes, incorporou o índio como factor identitário e alternativo ao património cultural ibérico (o caso brasileiro é aqui paradigmático), a verdade é que a dinâmica independentista estava essencialmente 
condicionada a uma mundividência ocidental, europeia e branca, e os ameríndios continuaram a ser relegados para uma posição dominada e subalterna.

$\mathrm{Na}$ senda dos sociólogos mexicanos Gonzaléz Casanova e Rodolfo Stavenhagen, e da pensadora boliviana Silvia Rivera Cusicanqui, Walter Mignolo designa por "colonialismo interno" este processo de subordinação dos novos Estados-Nações às grandes potências metropolitanas e de perpetuação das elites brancas no poder em detrimentos dos povos indígenas. Porém, ele alarga o horizonte temporal e espacial do conceito, que até então estava mais confinado às experiências independentistas dos países latinoamericanos do século XIX ou ao caso boliviano durante todo o século XX. Segundo Mignolo:

A construção da nação, tanto no século XIX nas Américas [...] quanto no século XX na África [...] e na Ásia [...], foi uma reconversão da colonialidade do poder de seu exercício no Estado colonial para sua nova forma sob o estado-nação. É precisamente essa reconversão que se poderia adequadamente descrever como "colonialismo interno". O colonialismo interno é a colonialidade do poder inserida no estado-nação após a descolonização, seja na América Latina do século XIX ou na África e na Ásia na segunda metade do século XX (MIGNOLO, 2013, p. 421).

Portanto, as situações histórico-políticas em que a debandada forçada dos poderes metropolitanos resulta em Estados-Nações independentes não é automaticamente uma via aberta para o enfrentamento com a colonialidade do poder existente no sistema mundial colonial/moderno, pois podem muito bem redundar em colonialismos internos, sejam eles levados a cabo por brancos contra ameríndios, por africanos contra africanos, por asiáticos contra asiáticos ou até por brancos contra brancos. ${ }^{1}$

Tendo em vista que estes processos também têm implicações e traduções no domínio da literatura, e que Mia Couto é um escritor que se forma num contexto póscolonial, o objectivo básico do presente trabalho consiste em avaliar como a problemática do "colonialismo interno" está inscrita em $O$ outro pé da sereia e, lateralmente, nas suas outras obras. Contribuirá o autor moçambicano para uma desmontagem desse colonialismo mediante uma crítica que também afecte a colonialidade do poder e remete para um pensamento de fronteira? Ficará ainda preso a ressaibos do ocidentalismo ou da negritude?

\footnotetext{
Para a questão das raízes e evolução do conceito de "colonialismo interno", cf., p. ex., Walter Mignolo, Histórias locais/Projectos globais. Colonialidade, saberes subalternos e pensamento liminar, trad. de Solange Ribeiro de Oliveira, Belo Horizonte, Editora da Universidade Federal de Minas Gerais, 2003, p. 150-152.
}

\section{Casuarino e outros agentes do colonialismo interno}

$O$ outro pé da sereia é um romance que se desenvolve mediante a técnica da "mise en abyme". Por um lado, narra a estória de Mwadia em busca de um lugar apropriado para guardar a Estátua de Nossa Senhora e recuperar a tranquilidade perdida. Por outro lado, integra aí os manuscritos quinhentistas que narram a viagem dos padres jesuítas D. Goncalo da Silveira e Manuel Antunes de Goa para o reino negro de Monomotapa, em Mocambique.

Embora o colonialismo interno seja uma categoria aplicada dentro de determinadas balizas cronológicas e pressuponha a formação de um Estado-Nação em ruptura com as forças metropolitanas que exploravam previamente o seu território, talvez se possa aqui utilizá-lo como um conceito analítico para pensar igualmente o plano quinhentista do romance de Mia Couto. Por certo, isso não colide com o facto de o plano contemporâneo da obra ser bem mais produtivo para a dilucidação da importância dessa categoria. Por certo, isso não se faz sem alguma precaução em virtude de haver aqui uma extrapolação do seu alcance nos autores atrás referidos. ${ }^{2}$ Porém, é sabido que, desde o início da expansão portuguesa e europeia em África, houve relações económicas e políticas de colaboração de alguns "sobas" e sectores privilegiados dos vários reinos negros com os colonizadores brancos. De colaboração que passava inclusive pelo tráfico de escravos e estava longe de se esgotar em alianças políticas conjunturais, em exploração de minérios e em troca de mercadorias. Em rigor, até mesmo depois da partilha imperialista de África via o Tratado de Berlim (1883) e da diminuição acentuada do espaço de manobra dos chefes negros prosseguiu a prática ancestral da articulação entre o poder dos colonos brancos e sectores minoritários da população indígena.

Por conseguinte, talvez não seja despropositado considerar que algumas figuras e situações inseridas na ficcionalização dos manuscritos quinhentistas pelo narrador de $O$ outro pé da sereia funcionam à guisa de antecedentes remotos dos Casuarinos e de outros agentes hodiernos do colonialismo interno. Não estão propriamente aqui em causa as personagens mais destacadas de Nimi Nsundi, de Dia Kumara e do escravo Xilundo, pois mantêm fortes tensões com os portugueses, chegam mesmo a abominá-los ou então possuem

\footnotetext{
2 Pensamos que a categoria de "colonialismo interno" não se esgota numa dimensão meramente diacrónica e pode ser entendida de modo analítico. Do mesmo modo o conceito do "pós-colonialismo" também extravasa da conjuntura posterior às independências e abrange todas as resistências à ideologia colonialista, ainda que produzidas em contextos coloniais e por autores das potências metropolitanas. Ver, p. ex.: LEITE, Ana Mafalda. Literaturas africanas e formulações pós-coloniais. Lisboa, Edições Colibri, 2003, p. 11.
} 
embrionariamente características dos seres de "fronteira". Estão, isso sim, em jogo figuras menos individualizadas e situações pouco desenvolvidas. Por exemplo, encontramos esses antecedentes remotos na alusão ao rei do Congo, Mbemba Nzinga (Afonso I), cuja governação estava condicionada por convergências com os portugueses na religião, no comércio e na política. A despeito de tímidos protestos, até alguns dos seus súbditos eram objecto do tráfico de escravos num contexto em que Mbemba Nzinga nunca rompeu com os colonizadores e sempre difundiu a fé católica. Aliás, no plano ficcional dos manuscritos quinhentistas de $O$ outro pé da sereia, o próprio Nimi Nsundi se torna escravo dos portugueses em função dos interesses do rei congolês (Cf. COUTO, 2006, p. 63). Por exemplo, encontramo-los também na instável política de alianças do Imperador de Monomotapa e do "mambo" Inhamoyo. Seja com os portugueses, com os árabes ou com outros, eles orientam mais o seu agir em função dos seus interesses comerciais e políticos do que em resultado das necessidades das populações autóctones, não hesitando também em promover o tráfico negreiro. Inhamoyo chega ao ponto de vender o próprio filho, Xilundo, a fim de industriá-lo no negócio da escravatura.

Bem mais importante para a perspectivação do papel do colonialismo interno neste romance de Mia Couto, a estória de Mwadia comporta várias personagens e situações que quase poderíamos classificar como antológicas. Excluindo o período colonialista e as figuras de Edmundo Esplendor Marcial Capitani, Inácio da Anunciação Rodrigues ou Agnelo Rodrigues, porque não cabem na categoria do colonialismo interno definida por Mignolo e outros, e são sobretudos seus antecedentes próximos enquanto tipos significativos dos muitos milhares de colaboradores negros e indianos da máquina administrativa e militar da potência metropolitana, as figuras que melhor se enquadram nessa categoria são Casuarino, alguns habitantes de Vila Longe e o feiticeiro Lázaro Vivo.

Empresário da capital, bem relacionado com a classe política no poder, a par dos mecanismos gerais da globalização, antigo anti-colonialista e oriundo de Vila Longe, Chico Casuarino parece ser o nó górdio do fenómeno do colonialismo interno em $O$ outro pé da sereia. A sua completa subordinação ao imaginário da colonialidade do poder e a sua mercadorização da existência como que o predispõem para principal arquitecto da ida da ONG norte-americana para Vila Longe. Confirmando o discurso do "outro" ocidental acerca da África exótica, animista e ainda pré-moderna, e meramente interessado em ganhar dinheiro com o projecto da ONG, ele leva Benjamin Southman e a esposa para Vila Longe num processo em que mercadorizará tudo, inclusive a cerimónia sagrada do "magoneko"e a própria estátua de Nossa Senhora/Kianda. "Project Budget", derrapagem orçamental, iniciativa privada, dólares e globalização, tais são os termos fundamentais da axiologia do empresário e que acabam por orientar boa parte da relação entre a comunidade local e a ONG. Neste contexto, Vila Longe, Moçambique, África e o sistema mundial colonial/moderno são distintas componentes de uma colonialidade do poder que também tem essa mesma lógica da voracidade da mercadorização da humanidade e de todos os bens materiais e simbólicos. Quando o casal Southman chega a Vila Longe, é precisamente isso que está sub-repticiamente em jogo e Casuarino desempenha aqui um papel de subordinação integral à globalização neo-liberal:

Casuarino avançou para o meio da praça, subiu a uma grade de coca-cola e, em tom solene e eufórico, proclamou:

- Isto é a globalização, my friends! A globalização mundial! Vila Longe é a capital da aldeia global (COUTO, 2006, p. 169).

Por outra palavras, Vila Longe parece tornar-se assim num espaço simbólico de uma relação entre o local e o global que não põe minimamente em causa a colonialidade do poder, e Casuarino configura-se como principal agente do colonialismo interno aberto às sobras das ONGs e à perpetuação da dependência externa do país. Aliás, não é por acaso que Arcanjo Mistura lhe diz: "Esta terra já não é nossa [...]. Talvez seja ali do Casuarino, mas nossa não é" (COUTO, 2006, p. 149) e que o próprio empresário se considera uma estrutura (Cf. COUTO, 2006, p. 172). Ele é meramente uma peça de um processo mais generalizado de subordinação das autoridades locais e centrais, dos meios empresariais e de outros sectores da sociedade moçambicana à colonialidade do poder. Emparelha com os Estêvão Jonas e os Assane de Terra sonâmbula, com os Vasto Excelêncio da Varanda do Frangipani ou com outros "administraidores" que constituem uma pequena elite especializada na inserção desigual e injusta do Estado-Nação moçambicano no sistema mundial colonial/moderno sem preocupação com as condições de vida das populações autóctones e com exclusivo interesse na acumulação privada de capital.

Embora em registos menos significativos, porque ocorrem em áreas menos próximas das elites políticoeconómicas do pós-independência e são mais pacientes do que propriamente agentes do fenómeno, alguns habitantes de Vila Longe também são configurados pela colonialidade do poder enquanto seus instrumentos internos após a independência e a descolonização do país.

No período colonialista, Zeca Matambira e Jesustino já estavam bastante assimilados devido ao cumprimento de funções administrativas ou comerciais enquadradas pelas 
redes sócio-estatais exercidas no território moçambicano pelo poder metropolitano. Agora eles continuam ainda amarrados ao imaginário dos colonizadores brancos. A Independência não lhes alterou substancialmente uma mundividência dominada pela cultura branca, cristã e ocidental. Por isso, Zeca Matambira é assim mencionado pelo narrador:

Zeca Matambira, nessa noite, cumpriu o ritual: mãos e cabelo, reza e pente. Antes de adormecer fez as orações. Em seguida, penteou-se. Depois, ficou contemplando o pente na concha das mãos. Era uma cerimónia que repetia religiosamente desde a Infância. Era no pente, como num espelho, que ele contemplava a sua raça. Tempos sem fim, estudava cada fio de cabelo que ficava prisioneiro nos dentes do pente. Tocava neles para os sentir crespos, enroscados como gavinhas de trepadeira. Aqueles fiozinhos, tão singelos, o empurravam para a certeza. Ele era um preto, tão irreversivelmente negro como todos os de Vila Longe. Depois, limpava o pente como se a si mesmo se lavasse. Como se o cabelo fosse uma sujidade na alma, a irrefutável prova de um crime sem perfeição (COUTO, 2006, p. 249).

Por isso, Jesustino colecciona nomes tipicamente portugueses e de forte feição cristã, é atormentado pela entropia do incesto com a irmã e interdita a leitura à enteada e à mulher. A despeito das potencialidades que lhe proporciona o seu cruzamento existencial entre indianos, africanos e portugueses, ele é incapaz de operar sínteses entre as raças ou entre a oralidade e a escrita. Formatado pela colonialidade do poder e pela sua ocidentalidade, Jesustino não actualiza as suas virtualidades e até o casamento com a negra Dona Constança redunda em dominação de género sem quaisquer frutos produtivos.

Por último, Lázaro Vivo também poderá ser enquadrado na categoria do colonialismo interno, não tanto por tirar proveito das novas tecnologias quanto por se adaptar de modo praticamente acrítico às modas mediáticoculturais e às ONGs impostas a partir de representações estereotipadas e deturpadas das realidades africanas. A tabuleta profissional do feiticeiro como que reproduz parte da linguagem e das práticas da globalização neoliberal aplicadas ao mundo rural africano: "Lázaro vivo, notável das comunidades locais, curandeiro e elemento de contacto para ONGs" (COUTO, 2006, p. 28). Crendices terapêuticas, conhecimento da flora e da fauna por vias mágicas e ancestrais, ONGs e pouco mais configuram as representações do "outro" acerca de África. Em vez de usar os avanços tecnológicos para construir alternativas económicas, sociais e culturais baseadas na sua interacção com uma gnose milenar que permite efectivamente conhecer as potencialidades agrícolas, farmacológicas, energéticas, industriais e outras da natureza, Lázaro
Vivo parece limitar-se simplesmente a uma perspectiva individual e mercantilizada que corrobora a distribuição do poder no sistema mundial colonial/moderno. Obviamente, não se trataria aqui de arquitectar conscientemente todo esse projecto alternativo, mas sim de dar pequenos passos comunitários rumo à sua futura efectivação sem mendigar às ONGs e sem questionar minimamente a recondução do africano a estádios civilizacionais pré-modernos ou mesmo primitivos. Para desmontar toda a farsa animista e selvagem forjada por Chico Casuarino e levada a efeito por Lázaro Vivo, o episódio em que este se apresenta a Benjamin Southman com todas as minúcias dos feiticeiros arcaicos resulta exemplar:

Para reforçar o clima exótico, [Casuarino] dirigiu-se ao curandeiro em si-nhungwé:

- Malaka tani, Ba Lázaro?

- Ali kupi nkuku? Ali kupi ntsima?

O empresário, mãos na cintura, como se tivesse acabado de praticar um feito heróico, traduziu para os americanos. Que ele, primeiro, tinha saudado o adivinho. E que Lázaro queria saber das galinhas brancas, da farinha, da bebida, enfim, dos condimentos para realizar a cerimónia. De um saco de viagem, Jesustino retirou os ingredientes requeridos e espalhou-os no chão.

- Só falta o tambor. Quer conferir?

$\mathrm{O}$ curandeiro dispensou a verificação. Com um largo sorriso, saudou o americano. E logo a seguir, em inglês e à queima-roupa, despachou a imediata pergunta:

- How is the dollar,my friend? (COUTO, 2006, p. 315)

Tendo o seu epicentro no empresário Chico Casuarino e espraiando-se ainda para outras personagens, o colonialismo interno atravessa boa parte de $O$ outro pé da sereia e encontra a sua desconstrução na caricatura das figuras e das situações que o configuram. Mas não passará também essa desconstrução por seres de "fronteira" e pelo trabalho do narrador em terceira pessoa interessado em fazer romances de tese contra a colonialidade do poder sem concessões aos seus servidores internos e à própria "negritude", ela ainda uma sobrevivência da categoria da "raça"?

\section{Negritude, personagens da "fronteira" e colonialidade do poder}

A longa história de escravidão, subordinação e discriminação das populações negras produziu um imaginário negativo que acabou por contaminar a visão que elas tinham sobre si mesmas. Nas primeiras décadas do século XX, a valorização da arte negra, o "jazz" e o movimento geral da "Harlem Renaissance" começaram a inverter essa negatividade. Em França, nos meados dos anos 30 , intelectuais de origem africana e afro-caribenha 
dão forma a uma imagem positiva do ser negro. Embora a sua origem se tenha dado por dentro da perspectiva mais histórico-cultural de Aimé Césaire, a "negritude" haveria de transitar da afirmação do direito dos negros terem igualmente o seu lugar na civilização mundial sem complexos de inferioridade para visões essencialistas e biológicas. Em discordância com o seu companheiro Césaire, o senegalês Senghor viria a considerar que os negros eram por essência mais abertos à natureza, aos ancestrais e à emotividade, construindo assim um discurso que reproduzia parcelarmente o imaginário do ocidentalismo acerca dos negros e virando-o agora em seu favor. Independentemente dessas versões mais ou menos essencialistas, o certo é que ambas assentavam basicamente na categoria de "raça" e esta não combina bem com a globalização das mestiçagens biológicoculturais que parece nortear o narrador de $O$ outro pé da sereia, algumas das suas personagens e o próprio Mia Couto. Quer para estes seres de papel, quer para o autor de carne e osso, as ideias de Frantz Fanon parecem muito mais ser o horizonte de enquadramento do que propriamente as de Senghor, de Césaire e da negritude. ${ }^{3}$ Por isso, Benjamin Southman carece de ser desmontado e balizado na sua subordinação à colonialidade do poder.

Afro-americano, historiador e mediador de projectos de ONGs, ele incorre numa série de equívocos a respeito das realidades africanas. Molda-as inconscientemente ao imaginário ocidentalista. Desconsidera a existência do fenómeno do colonialismo interno. Desconhece a necessidade de pensar por fora da raça. Num dos seus primeiros contactos com o mundo africano, ele e a mulher são imediatamente colocados diante de uma modernidade que invade Moçambique e que não se encaixa nos estereótipos do arcaísmo:

No primeiro trecho da estrada, os americanos se espantaram: em lugar da extensão solitária e abandonada, reinava ali um formigar de gente, um fervilhar de vendedores ambulantes, de carrinhas apinhadas de passageiros, de camiões carregando troncos de árvores milenares. Todos os veículos seguiam a estonteante velocidade, desafiando as mais elementares regras de segurança. Benjamin sorriu: ainda há pouco, do alto do avião, ele antecipava estar visitando o lugar do sossego e dos vagares. Enganara-se. Não era senão o primeiro de uma longa série de equívocos (COUTO, 2006, p. 164).

A explicação de todos os males dos negros reduzida apenas ao fenómeno histórico da escravatura,

\footnotetext{
3 Para uma breve introdução a esta questão da "negritude", cf. Eurídice Figueiredo e outros, "Negritude, Negrismo e Literaturas de Afrodescendentes", in Eurídice Figueiredo (org.), Conceitos de literatura e cultura, Juiz de Fora/Niterói, Editora da Universidade Federal de Juiz de Fora/Editora da Universidade Federal Fluminense, 2005, p. 313-340.
}

a identificação exclusivista do tráfico negreiro com a acção dos brancos, a relação animista com a natureza ou o contacto privilegiado com as espiritualidades ancestrais, tudo isto funciona como lugares-comuns que obstruem a compreensão das multifacetadas realidades que perpassam o continente africano. Poderão dar conta de uma parte das comunidades rurais, mas não esgotam a sua complexidade e ainda menos se aplicam aos meios urbanos. No fundo, reproduzem o imaginário da colonialidade do poder e excluem a modernidade, a racionalidade e as alianças socio-economicas alheias à mera categoria de "raça" do horizonte do mundo africano. Por isso, Arcanjo Mistura diz a Benjamin Southman: "Nós temos de lutar para deixarmos de ser pretos, para sermos simplesmente pessoas" (COUTO, 2006, p.219). Manifestando uma enorme dificuldade para entender esta aversão por qualquer mundividência centrada na raça e aferrando-se à negritude, Benjamin Southman é, portanto, um obstáculo à proposta de mestiçagem global e à desmontagem de qualquer forma de colonialidade do poder, ainda que levada a cabo por agentes internos a coberto da raça, da etnia ou da nacionalidade. Para o fim da narrativa, ele e a suposta esposa baqueiam nas suas construções estereotipadas, revelando-se inclusive como farsantes a quem a realidade ensinara uma lição e principiara a modificar.

Ao contrário destas personagens, que não se mostravam aptas para desmontar a colonialidade do poder e a sua reconversão no colonialismo interno, há outras cuja dinâmica e localização existenciais apontam precisamente para essa desmontagem. Não obstante o facto de Nimi Nsundi ou o padre Manuel Antunes poderem ser aqui incluídos, pois ambos assumem uma condição fronteiriça que mistura religiões, culturas e raças, estamos em crer que o plano histórico em que se situam e o seu elevado grau de inverosimilhança aconselham uma abordagem prudente. Eles não podem ser as principais personagens da "fronteira" e só como manipulações anacrónicas do narrador servem esse propósito, interessando-nos mais desenvolver outras figuras com maior consistência histórica e já claramente postuladas em situação póscolonial.

Aqui surge essencialmente Mwadia Malunga e a sua demanda de lugar seguro para a imagem da Santa. Por ela passa o nó górdio da "fronteira", do "entre-lugar" ou do "pensamento liminar", se por estes conceitos entendermos dinâmicas de mestiçagem global e de confrontação com a colonialidade do poder. Muito embora Constança Malunga e Arcanjo Mistura também tenham características de personagens de "fronteira", tendo até aquela a mais-valia de trazer a terreiro as questões do género e da orientação sexual, e incarnando aquele a persistência dos ideais utópicos postulados pela dinâmica 
independentista de meados dos anos 70, nenhum dos dois cumpre o papel de Mwadia. A sua mãe traz problemáticas impensáveis à luz dos estereótipos que as várias formas da colonialidade do poder projectam sobre as mulheres africanas, mas não lhe cabe a ela a dimensão futurante que a filha anuncia. O barbeiro revolucionário desconfia dos americanos e das ONGs, desmonta a categoria de "raça" e carrega a memória dos projectos revolucionários, mas não tem cabimento na actualidade. Por entre a corrupção das autoridades estatais, a entrega dos recursos do país à voragem do mercado neo-liberal e o descalabro do mal-chamado "socialismo real", ele acaba louco. Aliás, o narrador já dera o mote para essa inviabilidade de Arcanjo Mistura no início do século XXI: "Falecera um tempo em que ele podia fazer amigos" (COUTO, 2006, p. 214). Ao contrário deles, Mwadia será, portanto, a canoa ou o rio de todas as travessias possíveis.

Pelo seu próprio nome, Mwadia como que é automaticamente associada às zonas fronteiriças em que as identidades não são estanques e estão em permanente negociação (Cf. COUTO, 2006, p. 22 e 276). Pelo seu nascimento, ela também se torna numa ponte entre o profano e o sagrado, entre os vivos e os mortos (Cf. COUTO, 2006:98-100). Pelo seu percurso existencial, ela espraia-se em sucessivas sínteses sem se confinar ao fechamento racional, religioso, racial, linguístico ou cultural. Era filha da escola, mas não desdenhava inteiramente das religiões e do animismo. Era negra, mas abria-se às outras raças e casara com um membro de outra etnia. Falava si-nhungwé, português e inglês. Pertencia ao campo e à cidade. Movia-se entre a oralidade e a escrita. A esta sua identidade movente alude o narrador quando escreve:

Pudesse a sua casa ser, como as demais, uma simples palhota de pau-a-pique, dessas que se desfazem sem ruído nem ruína. Mas a vida de Mwadia fez-se de contra-sensos: ela era do mato nascera em casa de cimento; era preta e tinha um padrasto indiano; era bela e casara com um marido tonto; era mulher e secava sem descendência (COUTO, 2006, p. 81).

Por isso, cabe-lhe a tarefa de reinstalar a Santa mulata no espaço africano e de transformar a sua demanda numa proposta de mestiçagem cultural por fora de qualquer entendimento exclusivista da raça ou de reducionismos históricos incapazes de atingir a colonialidade do poder nos seus desdobramentos internos. Ao terminar a caminhada, Mwadia ganha uma consciência clara da condição fronteiriça que a marca a ela e à Santa:

$\mathrm{Na}$ ida, ela se preocupara em sombrear a Virgem. No regresso, ela já ganhara a certeza: ali estava a Santa mulata, dispensando o sombreiro, afeiçoada ao sol de África.Chegada a um largo embondeiro, ela dirigiu o concho para a margem e foi subindo a ravina, carregando com ela a Santa. Junto ao tronco, ela depositou a Virgem, se ajoelhou e disse:

- Você já foi Santa. Agora, é sereia. Agora, é nzuzu.

Depois, Mwadia amarrou no braço da estátua o lenço que recebera de avó esclavagista. Junto ao único pé da Santa ela deixou a caixa do rapé da avó escrava (COUTO, 2006, p. 379-380).

Nesta sua maneira de ser africana e de falar "in situ”, Mwadia Malunga instaura a convivência de várias identidades que não podem ser confinadas a quaisquer monolitismos raciais, étnicos, nacionais, religiosos, linguísticos ou racionais. Nela, todas estas categorias flúem em permanente negociação e exigem trocas histórico-culturais incompatíveis com as representações simplistas do imaginário da colonialidade do poder, com a subordinação interna de Casuarino e com a negritude de Benjanin Southamn. Neste contexto, percebe-se bem que a sua infertilidade e a sua síntese superior não quadrem com os estereótipos da mulher africana como ser reprodutor, supersticioso e objectualizado. Num diálogo significativo, e logo no segundo capítulo do romance, Lázaro Vivo e ela digladiam-se a pretexto de uma certa incredulidade religiosa e postura emancipada que a perpassam:

- Há muito tempo que lhe queria dizer isto, Mwadia Malunga: você ficou muito tempo lá no seminário, perdeu o espírito das nossas coisas, nem parece uma africana.

- Há muitas maneiras de ser africana.

- É preciso não esquecer quem somos...

- E quem somos, compadre Lázaro? Quem somos? (COUTO, 2006, p. 55)

Como Kindzu, Muidinga/Gaspar ou Junhito, em Terra sonâmbula, como Ermelindo Mucanga e o detective Izdine, em $A$ varanda do Frangipani, ou o italiano Massimo Rissi, em $O$ último voo do flamingo, Mwadia não só leva a cabo a desconstrução simbólica do colonialismo interno, como também se projecta numa dinâmica fronteiriça apta a pensar outro mundo possível. Contra os Assane, os Estêvão Jonas, os Vasto Excelêncio e outros instrumentos de uma colonialidade do poder que quer forçar os africanos a identidades pré-modernas, menoridades políticas e desqualificações científicoculturais, estas personagens de fronteira afirmam solidariedades de raças, etnias, línguas, religiões, culturas e saberes.

\section{Conclusão}

Em 2001, num discurso pronunciado na Fundação Calouste Gulbenkian, Mia Couto remetia Terra sonâmbula 
e outros dos seus romances para um mesmo horizonte:

A terra, a árvore, o céu: é na margem desses mundos que tento a ilusão de uma costura. É uma escrita que aspira a ganhar sotaques do chão, fazer-se seiva vegetal e, de quando em quando, sonhar o voo de asa rubra. É uma resposta pouca perante os fazedores de guerra e construtores da miséria. Mas é aquela que sei e posso, aquela em que apostei a minha vida e o meu tempo de viver (COUTO, 2004, p. 230-231).

Em Terra sonâmbula, a escrita faz-se terra com Kindzu, Muidinga/Gaspar e Junhito, pois todos eles agem ou têm potencialidades para contrariar as forças de ódio e separação que se escondem detrás da guerra civil (cf. COUTO, 1992, p.218). Em Varanda do Frangipani, o narrador-defunto Ermelindo Mucanga recupera a pátria depois de ter sido instrumentalizado pelo colonialismo e de incarnar num inspector que, depois de todo um percurso de aprendizagem mediante o qual vem a respeitar o mundo dos ancestrais, da fantasia, da oralidade e da convivência racial, joga toda a sua rectidão ética no difícil contexto da corrupção generalizada. Ele acaba por morrer, mas Mucanga faz-se árvore em uníssono com a possibilidade de regeneração do país. Já não está objectualizado pela metrópole portuguesa e resiste aos esforços que os agentes do colonialismo interno fazem no sentido de transformar os seus restos mortais em símbolo de uma independência meramente formal (Cf. COUTO, 1996, p. 150-151). N' O último voo do flamingo, o italiano Massimo Rissi presta-se à mestiçagem quando deixa Temporina grávida e se irmana com o seu tradutor moçambicano negro na dinâmica de deperecimento metafórico do país, que já estava livre da guerra, mas não de múltiplas injustiças e problemas. Lançando as folhas de papel em que escreviam num abismo e transformando-as em flamingos de papel, eles fundem a escrita com um reinício mágico da pátria condicionada pelos oportunistas de sempre e em trânsito para outras possibilidades mais construtivas (Cf. COUTO, 2004, p. 219-225).

Neste contexto, não é possível desligar as obras de Mia Couto e $O$ outro pé da sereia daquilo a que se chama "romance de tese". Neste caso, a tese passa pela proposta de mestiçagens e misturas globais alheias à lógica exclusivista das raças, das etnias, das nacionalidades, das religiões ou das ideologias, exigindo obviamente o combate contra a colonialidade do poder e a sua transmudação pós-colonial em estruturas estatais a ela subordinadas. No fundo, isto ecoa o próprio percurso existencial de Mia Couto. Num dos artigos coligidos em Pensatempos, o escritor moçambicano escreve:
O meu país tem países diversos dentro, profundamente dividido entre universos culturais e sociais variados. Sou moçambicano, filho de portugueses, vivi o sistema colonial, combati pela Independência, vivi mudanças radicais do socialismo ao capitalismo, da revolução à guerra civil. Nasci num tempo de charneira, entre um mundo que nascia e outro que morria. Entre uma pátria que nunca houve e outra que ainda está nascendo. Esta condição de um ser de fronteira marcou-me para sempre. As duas partes de mim exigiam um médium, um tradutor. A poesia veio em meu socorro para criar essa ponte entre dois mundos distantes (COUTO, 2005, p. 106).

Militante da causa independentista e das utopias igualitárias, desiludido pela caricatura marxista da FRELIMO e pela guerra civil, espartilhado por várias identidade distintas e condicionado ao desencanto da absolutização do mercado em detrimento da soberania popular, Mia Couto continua a pugnar por alternativas civilizacionais estranhas à lógica da colonialidade do poder e do colonialismo interno. Sem soluções importadas e autoritariamente impostas, refugia-se em mestiçagens e misturas intrinsecamente ligadas às realidades socioculturais, mas ainda desprovidas de forca suficiente para alterar o status quo.

$\mathrm{Na}$ senda de Mariategui, Kusch, Fanon, o próprio Mignolo ou de escritores como Garcia Márquez, Juan Rulfo, Guimarães Rosa e Pedro Arguedas, ele postula um imaginário de "fronteira" entre oralidade e escrita, magia e razão, tradição e modernidade, campo e cidade, raças e etnias. Aqui fica de fora a cientificidade do sujeito neutro e universal que a ocidentalidade instrumentalizou ao serviço das forcas económicas dominantes, ou seja, da colonialidade do poder em todos os seus desdobramentos. Ao fazê-lo, Mia Couto produz grãos de areia literária vocacionados para a inscrição da voz dos dominados nas estruturas do poder e para a impugnação de quaisquer monolitismos raciais, étnicos, nacionais, religiosos, linguísticos ou culturais. As alianças não se devem fazer pela cor da pele, pela religião ou pela nacionalidade, mas sim por aqueles que estão subalternizados no contexto da colonialidade do poder e do colonialismo interno. Estas parecem ser as principais propostas de $O$ outro pé $d a$ sereia e das outras obras de Mia Couto.

A nosso ver, a aplicação das categorias de Walter Mignolo e de outros pensadores de "fronteira" a estas obras escritas na situação pós-colonial moçambicana revela-se da maior pertinência. $\mathrm{O}$ colonialismo interno mostra-se conceito muito compatível com uma realidade em que as elites político-económicas do país importam modelos forâneos à margem de qualquer interesse pelas populações autóctones e em prol dos projectos globais da colonialidade do poder. Tal como os seus antecessores 
latino-americanos do século XIX usaram a dinâmica independentista para edificar uma arquitectura jurídico económica em nítido descaso dos ameríndios e em proveito próprio, agora as elites negras fazem o mesmo com as massas populares que apenas têm em comum consigo a cor da pele e não os interesses ou os saberes. Por seu turno, a noção de "fronteira" cumpre aqui o papel de extravasar o horizonte limitado da "negritude" e de veicular mestiçagens em aberto contra todos os exclusivismos e dicotomias.

Mesmo a terminar, deixamos apenas estas questões. Não serão o colonialismo interno e a colonialidade do poder decorrentes da tradição do materialismo histórico, pois foi ela a analisar a sociedade em termos classistas e em ruptura com universalismos religiosos, racionais e raciais? Não será a colonialidade do poder uma outra maneira de dizer imperialismo? Não será a fronteira um conceito permutável com o de internacionalismo? Terá sido mero acaso que um dos primeiros pensadores de "fronteira" fosse Mariategui, marxista e internacionalista aberto aos ameríndios e a todos os progressistas dos países metropolitanos interessados em combater as múltiplas formas da colonialidade do poder? Será que o lugar ou "entre-lugar" geográficos donde se fala são mais importantes do que as suas contrapartidas socioeconómicas?

\section{Referências}

COUTO, Mia. Terra sonâmbula. Lisboa: Caminho, 1992. . Varanda do Frangipani. Lisboa: Caminho, 1996. 2004 O último voo do flamingo. 4. ed. Lisboa: Caminho,

Pensatempos. 2. ed. Lisboa: Caminho, 2005. O outro pé da sereia. Lisboa: Caminho, 2006.

FIGUEIREDO, Eurídice (Org.). Conceitos de literatura $e$ cultura. Juiz de Fora/Niterói: Editora da Universidade Federal de Juiz de Fora/Editora da Universidade Federal Fluminense, 2005.

LEITE, Ana Mafalda. Literaturas africanas e formulações pós-coloniais. Lisboa: Colibri, 2003.

MIGNOLO, Walter, Histórias locais/Projectos globais. Colonialidade, saberes subalternos e pensamento liminar. Trad. de Solange Ribeiro de Oliveira. Belo Horizonte: Editora da Universidade Federal de Minas Gerais, 2003.

Recebido: 01 de junho de 2016.

Aprovado: 15 de junho de 2016.

Contato: joaoalbertoalves@campus.ul.pt 